ORIGINAL ARTICLE

AFRICAN JOURNAL OF CLINICAL AND EXPERIMENTAL MICROBIOLOGY

MAY 2008 ISBN 1595-689X VOL 9 No 2

AJCEM/200822/20813

-http://www.ajol.info/journals/ajcem

COPYRIGHT 2008

AFR. J. CLN. EXPER. MICROBIOL. 9 (2): 97 - 102

\title{
ONCHOCERCIASIS AMONGST CHILDREN OF AN ENDEMIC COMMUNITY IN EDO STATE, NIGERIA
}

\author{
*Aisien ${ }^{1}$, M.S.O., Adeyemi ${ }^{1}$, E.E. and Wagbatsoma ${ }^{2}$, V.A. \\ ${ }^{1}$ Laboratory of Parasitology Research, Department of Animal \& Environmental Biology, Faculty of Life Sciences, \\ University of Benin, Benin City, Nigeria \\ ${ }^{2}$ Department of Community Health, Faculty of Medicine, University of Benin, Benin City, Nigeria.
}

*Corresponding Author: E-Mail: aisien@uniben.edu 푤 234-8023397370

\begin{abstract}
Onchocerciasis among 278 children (0-15yrs) of Ekpan village, a hyperendemic community in Uhunmwode Local Government Area of Edo State, Nigeria was investigated using the prevalence of nodules as index. The overall prevalence of palpable nodules was $26.3 \%$. Nodule prevalence increased with age and the association was found to be statistically significant $(\mathrm{P}<\mathbf{0 . 0 0 1})$. More males than females presented with onchocercal nodules; and the difference was also found to be statistically significant $(\mathrm{P}<\mathbf{0 . 0 5})$. Majority of the nodules found were located on the head, followed by the abdomen. Of the 186 children eligible to take ivermectin, only $124(66.7 \%)$ actually took the drug. The efficacy of ivermectin against onchocerciasis is demonstrated in the observation that those who took the drug presented with fewer nodules. Therefore, a timely introduction of eligible children ( $>5 \mathrm{yrs})$ to the treatment programme is advocated.
\end{abstract}

KEY WORDS: Onchocerciasis, children, Nigeria, nodules, prevalence, ivermectin.

\section{INTRODUCTION}

Ochocerciasis is a serious health and socioeconomic problem in Nigeria and other West African countries (1-3). It affects mostly the rural population, among who are the farmers who produce the bulk of food and industrial raw materials. Nigeria is estimated to have $30-40 \%$ of the world's cases or $60 \%$ of the cases in West Africa (4). Studies by Gemade et al. (3) showed that the disease was more widely distributed in Nigeria than previously assumed. The study provided accurate estimates of the population living in high risk areas of the disease. In the process, the team also identified communities to be given priority in the treatment with ivermectin.

Mass treatment with ivermectin in endemic communities usually excludes among others children below 5 years of age, although this group may constitute a sizeable proportion of some communities. According to Akogun (5), children under 10 years of age with head nodules have serious and irreversible eye lesions which significantly affect their visual acuity. Moreover, such an untreated population of children along with adults refusing to participate in community treatment programme with ivermectin, could constitute a steady reservoir for the re-infection of the treated population. In view of the little attention that has been given to this segment of the population, we undertook an investigation of onchocerciasis in the children of a hyper-endemic community in Edo State of Nigeria, using the presence of palpable nodules as our index. 


\section{SUBJECTS AND METHODS}

\section{Study Area}

The study was carried out in Ekpan village, located in Uhunmwode Local Government Area of Edo State, Nigeria. The village is located in the rainforest zone of Nigeria between longitude $5^{\circ} 56.660^{\prime} \mathrm{E}$ and latitude $6^{\circ} 43.210^{\prime} \mathrm{N}$ at an elevation of $279 \mathrm{~m} \mathrm{ASL}$ as determined using the Garmin III Plus Global Positioning System (GPS). The inhabitants of the community are predominantly farmers with a population of 643 at the time of this study.

\section{Advocacy and mobilization}

Advocacy visits were paid to the community head, seeking consent for the survey. Consent to undertake the survey was granted after the objectives of the study were highlighted. Mobilization of the community for the survey was undertaken by the Community Directed Distributor of ivermectin (CDD) on the directives of the village head and elders committee.

\section{Sampling method}

There were 643 individuals in Ekpan village, which constituted the entire population. The mean number of the residents per house was 6 while the mean number of children (0-15yrs) per house was 3. A sample size of 264 was derived from a microfilaria prevalence of $77 \%$ (6) with an added $10 \%$ to improve the response rate to $90 \%$, giving a final sample size of 293. All children 0-15yrs born in the community were eligible to participate in the study. However, only 278/293 consented to participate in the survey, giving a $94.8 \%$ response rate. The participants were examined from their head to the feet for the presence of palpable nodules. Number of observed nodules and site of occurrence were noted and recorded. Examination for palpable nodules was undertaken in individual participant's houses under minimal privacy.

\section{Data collection and analysis}

Data collected were analyzed using PEPI (7), the computer programme for epidemiological studies and association was established using the Pearson's Chi-square test.

\section{RESULTS}

Prevalence of nodules by age and sex

A total of 278 children comprising 133 (47.8\%) males and $145(52.2 \%)$ females were studied in Ekpan village (Table 1). The ages of the children ranged from 0-15 years with a majority, 150 $(54.0 \%)$ in the 5-10 years age group, followed by those in the 0-4 years age with 92 (33.1\%). The overall prevalence of palpable onchocercal nodules was $26.3 \%$. The prevalence of palpable nodules among the affected children increased with age as also shown in Table 1 and the association was found to be statistically significant $(\mathrm{P}<0.001)$. More males than females presented with palpable onchocercal nodules; and the difference was also found to be statistically significant $(\mathrm{P}<0.05)$.

\section{Distribution of nodules on the affected children}

Figure 1 shows the distribution of palpable nodules in different parts of the body of the affected children. Majority 60 (21.6\%) of the nodules were located on the head, followed by the abdomen with $44(15.8 \%)$ and the thorax with $38(13.7 \%)$.

\section{Ivermectin intake and nodule prevalence}

Table 2 shows that $92(33.1 \%)$ of the children studied were underfives and these were not eligible to take ivermectin. The children eligible for ivermectin were the $186(66.9 \%)$ who were 5 years and above and of this number only 124 (66.7\%) of them actually took the drug. Table 3 shows the prevalence of palpable nodules among children who were eligible for ivermectin. Prevalence of 
palpable onchocercal nodules was higher among the untreated than in the treated and the difference was found to be statistically significant $(\mathrm{P}<0.000)$.

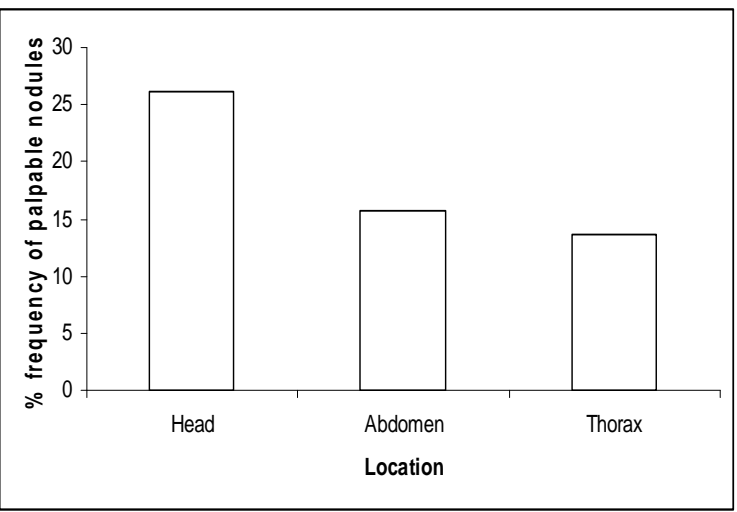

Fig. 1. Distribution of palpable nodules on the body of affected children in Ekpan village
Table 1. Overall prevalence of palpable nodules among the children of Ekpan village by age and sex.

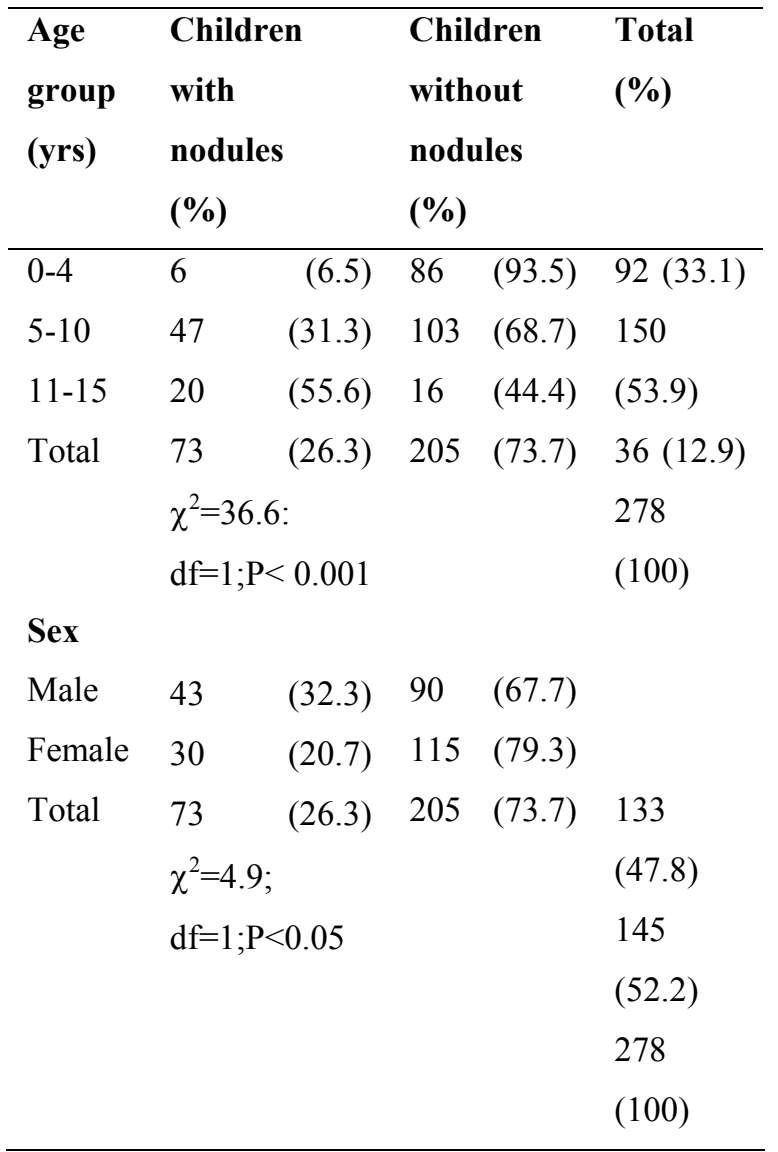

Table 2. Age, ivermectin intake and frequency of palpable nodules among the children of Ekpan village

No and \% frequency of

Age $\quad$ No \& $\%$ ivermectin ntake

(yrs) examined Yes No

$\begin{array}{lllll}<5 & 92(33.1) \quad-\quad & 92 \quad(100)\end{array}$

$>5 \quad 186(66.9) \quad 124(66.7) \quad 62(33.3)$

Total $278(100) \quad 124(44.6) \quad 154(55.4)$
Table 3. Prevalence of palpable nodules among children eligible to receive ivermectin treatment

\begin{tabular}{|c|c|c|c|}
\hline \multicolumn{4}{|c|}{ No and \% frequency of nodules } \\
\hline $\begin{array}{l}\text { Eligible } \\
\text { children }\end{array}$ & $\begin{array}{l}\text { Nodules } \\
\text { present }\end{array}$ & $\begin{array}{l}\text { Nodules } \\
\text { absent }\end{array}$ & Total \\
\hline Treated & $16(12.9)$ & $108(87.1)$ & $124(66.7)$ \\
\hline Not treated & $51(82.3)$ & $11(17.7)$ & $62(33.3)$ \\
\hline Total & $67(36.0)$ & $119(64.0)$ & $186(100)$ \\
\hline
\end{tabular}




\section{DISCUSSION}

The use of palpable onchocercal nodule prevalence as index for determining the level of endemicity in communities has been in practice since its validation in Nigeria $(8,9)$ except that it was used for adults and the threshold for treatment in endemic communities set at $20 \%$ (10). Following its validation in Nigeria, nodule palpation became the method of choice for rapid community diagnosis of onchocerciasis and its validity has since been confirmed by several independent studies (11-13). For our study, the attractiveness of this method lay in its noninvasiveness as against skin-snipping which is resented among the adult population and dreaded by children. Other reasons for which nodule palpation has been recommended include its simplicity, applicability and practicability, acceptability and non-technicality $(3,11,13,14,15)$. Furthermore, this method has been found to reduce blood transmissible infections such as HIV/AIDS and hepatitis B $(16,17)$.

The overall prevalence of nodules among the children studied was $26.3 \%$ compared with the $38.7 \%$ in the adult population from the same study location (18). This result pattern, which has also been observed elsewhere (19) shows that infection is acquired early in life in this community.

The prevalence of nodules was observed to increase with age. This observation conforms to the pattern of the disease (5,19-26). Consequently, in hyper-endemic communities such as Ekpan, where transmission is already intense at young age, the process of early infection may predispose most individuals to acquiring increasingly higher worm burden as age progresses (12). Differences observed in the prevalence of nodules between male and female children tend to suggest that male children are more exposed to infective bites. In farming communities such as Ekpan it is common practice for young males to accompany their fathers to work in the farm thus exposing them more to Simulium bites. This observation is in good agreement with those of Brabin (27) who concluded that any gender-specific differences in symptomatology and microfilarial densities derive from differences in exposure rather than from inherent sex differences.

On the distribution of nodules, it was observed to be more on the head and trunk of the children studied. In Africa where S. damnosum and $S$. neavvei complexes bite mainly on the ankles and legs of adults, nodules are most commonly located around the pelvics. In children however, because their head is closer to the ground than those of the adults, it makes the head and trunk the likely sites open to infective bites (28). Moreover, the head of infants may be the only area exposed when on their mother's back or when laid on the ground while their mothers are busy with farming (28).

With the low prevalence of nodules among the underfives (Table 2), it is obvious that this group does not constitute a significant source of infection in the community. This is in good agreement with the observations of Duke and 
Moore (20) who in their study of different age groups in a Cameroon forest village concluded that apart from occasional individuals, children under 5 yrs are of little importance as a source of transmission. This cannot be said of children, 5 yrs and above, who are infected and very accessible to Simulium flies when they engage in farming and other outdoor activities in the community. If this segment of the population is neglected in the ongoing ivermectin treatment programme in the community, they may constitute a good reservoir of infection and reinfection for the treated population. It needs to be stressed that adults in the community need to take the annual treatment programme more seriously as this will effectively reduce the microfilariae available for transmission to the younger members of the community.

From the results presented in Table 3, it is obvious that ivermectin is efficacious in the control of onchocerciasis as children who took the drug presented with fewer nodules. Apart from the microfilaricidal effect of ivermectin, the drug has been shown to reduce fecundity and cause death of as much as $30 \%$ of adult Onchocerca volvulus $(29,30)$. From the foregoing, it is obvious that timely introduction of eligible children (5yrs and above) in endemic communities to ivermectin treatment will reduce morbidity and the clinical manifestations of the disease.

\section{REFERENCES}

1. Prost A. The burden of blindness in adult males in the savanna villages of West Africa exposed to onchocerciasis. Trans. Soc. Trop. Med Hyg. 1986; 80:522-527.
2. Nwoke BEB. The socio-economic aspects of human onchocerciasis in Africa. Present Appraisal. J. Hyg. Epidemiol. Microbiol. Immunol. 1990; 34:37-44.

3. Gemade EI, Jiga NY, Nwoke BEB, Ogunba EO, Edeghere H, Akoh JI and Omojola A. Human onchocerciasis: Current assessment of the disease burden in Nigeria by rapid epidemiological mapping. Ann. Trop. Med. Parasitol. 1998; 92(1):79-83.

4. Abiose A. Operational research for ivermectinbased onchocerciasis control in Nigeria. Nig. J. Ophthamol. 1993; 2:32-37.

5. Akogun, OB. Eye lesion, blindness and visual impairment in the Taraba valley, Nigeria and their relation to onchocercal microfilariae in skin. Acta Tropica 1994; 51:143-149.

6. Nmorsi P and Obiamiwe BA. Onchocerciasis in Imeri, Ondo State, Nigeria. Nig. J. Parasitol. 1992; 13:43-49.

7. Gahlinger PM and Abrahamson JH. Computer Programmes for Epidemiological Analysis. Makapu Medical Press. 1993; 40-48.

8. TDR. Methods for community diagnosis of onchocerciasis to guide ivermectin-based control in Africa 1992. TDR/TDE/ONCHO/92.2, WHO, Geneva.

9. Remme JHF. Research for control: the onchocerciasis experience. Trop. Med. Int. Hlth. 2004; 9(2):243-254.

10. Taylor HR, Duke BOL and Munoz B. The selection of the communities for treatment of onchocerciasis with ivermectin. Trop. Med. Parasitol. 1992; 43:267- 270.

11. Whitworth JAG and Gemade EI. Independent evaluation of onchocerciasis, rapid assessment methods in Benue State, Nigeria. Trop.Med. Int. Hlth. 1999; 4:26-30.

12. Vivas-Martinez S, Bezanez MG, Bolton C., Garcia M., Pacheco $M$ and Curtis CF. Parasitological indicators of onchocerciasis relevant to ivermectin control programmes in the 
Amazonian focus in Southern Venezuela. Parasitology 2000; 121(5):527-534.

13. Kipp W and Bamhuhiiga J. Validity of nodule palpation in Simulium neavei transmitted onchocerciasis area in Uganda. Am. J. Trop. Med.

Hyg. 2002; 76 (1):128-131.

14. Edungbola LD, Nwoke BEB, Onwuliri COE, Akpa AUC and Tayo-Mafe M. Selection of rapid assessment methods for community diagnosis of onchocerciasis in Nigeria. A recapitulation. Nig. J. Parasitol. 1993 14:3-6.

15. Albiez EJ, Buttner DW and Duke BOL. Diagnosis and extirpation of nodules in human onchocerciasis. Trop. Med. Parasitol. 1988; 39:331-346.

16. WHO. Methods for community diagnosis of onchocerciasis to guide ivermectin-based control in Africa: Report of an informal consultation held in Ouagadougou 19-21 November, 1991, TDR/JJDE/ONCHO/92.2, Geneva.

17. Nwoke BEB, Edungbola LD, Mencias BS, Njoku AJ, Abanobi OC, Nkogwu FU, Nduka FO and Oguariri RM. Human onchocerciasis in the rainforest zone of south-eastern Nigeria I: Rapid assessment methods for community diagnosis in the Imo River Basin, Nigeria. Nig. J. Parasitol. 1994; 15:7-18.

18. Wagbatsoma VA and Aisien MSO. Ivermectin distribution, coverage and associated factors in Ekpan village, Edo State, Nigeria. Nig. J. Parasitol. 2001; 22(1\&2):157-162.

19. Nwaorgu OC and Okeibunor JC. Onchocerciasis in pre-school in Nigeria: Lessons for onchocerciasis control programme. Acta Tropica 1999; 73(3):211-215.

20. Duke BOL and Moore PJ. The contributions of different age groups to the transmission of onchocerciasis in a Cameroon forest village. Trans. Roy.Soc. Trop. Med. Hyg. 1968; 62(1):2228.

21. Dipeolu OO and Gemade EI. Onchocerciasis in Benue State of Nigeria IV. The prevalence of the disease among the population in Manor. International Zoonoses 1983; 10(1):85-95.

22. Kirkwood B, Smith P, Marshall T and Prost A. Variation in the prevalence and intensity of microfilarial infections by age, sex, place and time in the area of onchocercal programme. Trans. Roy. Soc.Med. Hyg. 1983; 77:857-861.

23. Maizels RM and Lawrence RA. Immunological tolerance; the key in human filariasis. Parasitology Today 1991; 7:271-278.

24. Nwaorgu OC. Visual acuity, microfilarial load, nodules and nutritional status among adults with onchocerciasis infections in south east Nigeria. Takemi Report, Havard School of Public Health $1995 \mathrm{a}$.

25. Nwaorgu OC. Onchocerciasis infection, onchocercomata, visual acuity and nutritional status in children in an endemic area of south eastern Nigeria. Takemi Report, Havard Schol of Public Health 1995b.

26. WHO. Epidemiology of onchocerciasis. Report of WHO expert committee 1976. Technical Report Series No 597, Geneva WHO.

27. Brabin L. Factors affecting the differential susceptibility of males and females to onchocerciasis. Acta Liedensia 1990; 59(1\&2):413-426.

28. Anderson J, Fuglsang H, Hamilton PJS and Marshall TF de C. Studies on onchocerciasis in the United Cameroon Republic II. Comparison of onchocerciasis in rainforest and Sudan savanna. Trans. Roy. Soc. Med. Hyg. 1974; 68:209-222.

29. Duke BOL, Zea-Flores G, Castro J, Cupp EW and Munoz B. Comparison of effects of a single dose and four six-monthly doses of ivermectin on adult Onchocerca vovulus. Am. J. Trop. Med. Hyg. 1991; 45:132-137.

30. Meredith SEO and Dull HB. Onchoceriasis: the first decade of mectizan treatment. Parasitology Today 1998; 14(2):472-474. 